\title{
Dual-Polarized Crossed Bowtie Dipole Array for Wireless Communication Applications
}

\author{
Zhi-Ya Zhang, ${ }^{1}$ Shuang Li, ${ }^{1}$ Shao-Li Zuo, ${ }^{2}$ Jia-Yue Zhao, ${ }^{1}$ Xiao-dong Yang, ${ }^{3}$ and Guang Fu ${ }^{1}$ \\ ${ }^{1}$ National Key Laboratory of Antennas and Microwave Technology, Xidian University, Xian, Shaanxi 710071, China \\ ${ }^{2}$ School of Physics and Optoelectronic Engineering, Xidian University, Xian, Shaanxi 710071, China \\ ${ }^{3}$ School of Electronic Engineering, Xidian University, Xian, Shaanxi 710071, China \\ Correspondence should be addressed to Zhi-Ya Zhang; zhiyazhang@163.com
}

Received 5 July 2014; Revised 2 October 2014; Accepted 10 October 2014; Published 26 November 2014

Academic Editor: Duixian Liu

Copyright (c) 2014 Zhi-Ya Zhang et al. This is an open access article distributed under the Creative Commons Attribution License, which permits unrestricted use, distribution, and reproduction in any medium, provided the original work is properly cited.

\begin{abstract}
A dual-polarized array with downtilted radiation patterns is proposed for wireless communication applications. The proposed dual-polarized antenna element achieves an enhanced impedance bandwidth and compact dimensions by introducing a parasitic circular patch and vertical metal cylinders, which is a good candidate for radiating elements in base station antennas. By optimizing the amplitude and phase distribution along the feed, a radiation pattern with a downtilted angle is obtained. The dual-polarized array antenna achieves an impedance bandwidth for VSWR $\leq 1.5$, covering the frequency bands for $3 \mathrm{G} / \mathrm{LTE}$ systems. Moreover, the proposed array achieves high port isolation, the stable antenna gain over the entire operating band. Therefore, the proposed array antenna is very suitable for potential wireless communication applications. A prototype has been manufactured and measured. The measurements, that match the design objectives, are also presented.
\end{abstract}

\section{Introduction}

With the rapid development of mobile communication systems, different mobile communication systems operating in different frequency bands have been designed. The 3G systems, such as TD-SCDMA, WCDMA, and CDMA2000, operate in the $2 \mathrm{GHz}(1880-2170 \mathrm{MHz})$ band [1], and the future LTE (Long Term Evolution, 4G) systems, such as TDD LTE and FDD LTE, will operate in the $2.3 \mathrm{GHz}(2300-$ $2400 \mathrm{MHz})$ and $2.6 \mathrm{GHz}(2570-2690 \mathrm{MHz})$ bands [2, 3]. Therefore, base station antennas must have a wide impedance bandwidth covering the frequency band from $1800 \mathrm{MHz}$ to $2800 \mathrm{MHz}$. In addition, for base station applications, dual orthogonal polarizations oriented at angles of $+45^{\circ}$ and $-45^{\circ}$ with respect to vertical direction are also required, as the signal on two orthogonal polarizations can help reduce the fading caused by multiple reflections $[4,5]$.

Recently, a great number of base station antennas have been developed. The dual-polarized antenna proposed in [6] is a combination of a modified low-profile monopole and a circular planar loop and it achieves an impedance bandwidth of about $25 \%$, being unsatisfactory to cover the LTE frequency bands. Dual-polarized wideband antennas also are proposed in [7-11]; however, the operating frequency bands of the proposed antennas cannot cover the $3 \mathrm{G}$ and LTE frequency bands. The broadband dipole antenna proposed in [12] is composed of an irregular shorted patch and planar dipole elements, which obtains a bandwidth of $49.5 \%$. The array may show grating lobes because the lateral dimension of the antenna is large. Therefore, it is difficult for these antennas to be designed as an array. Similarly, the wideband antennas proposed in [13-18] are difficult to be arrayed. Moreover, in [19], although the proposed wideband antennas have a compact size, they have a complex structure, which leads to high cost and difficulty in postfabrication tuning. In [20, 21], a downtilted radiation pattern for base station applications is achieved.

In this paper, a dual-polarized crossed bowtie dipole array is presented. The array antenna element consists of a pair of dipoles, inverted L-shaped feed strips, a parasitic circular patch for impedance enhancement, and vertical metal cylinders for decreasing the lateral dimensions. A wide impedance 


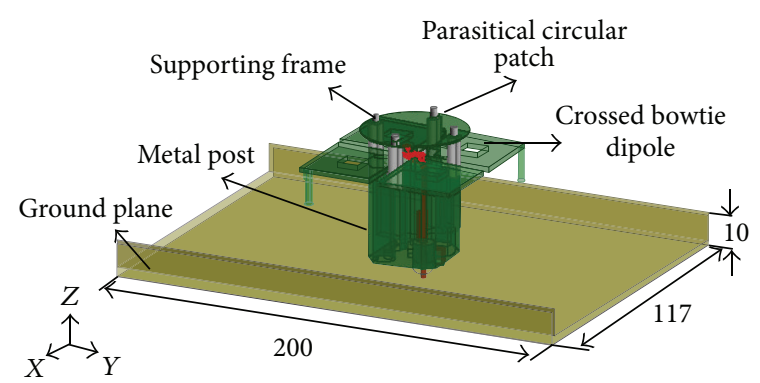

(a)

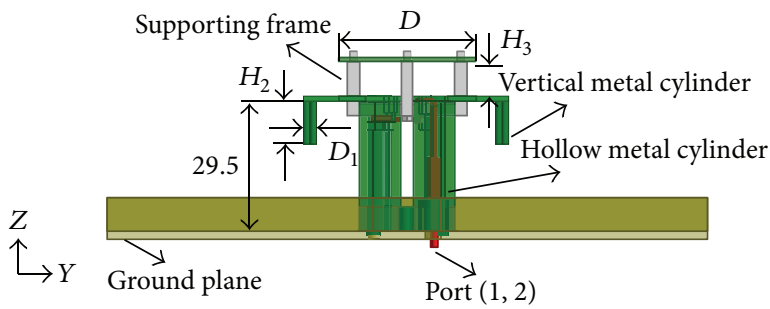

(b)

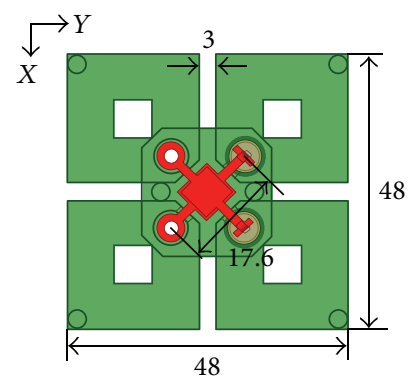

(c)

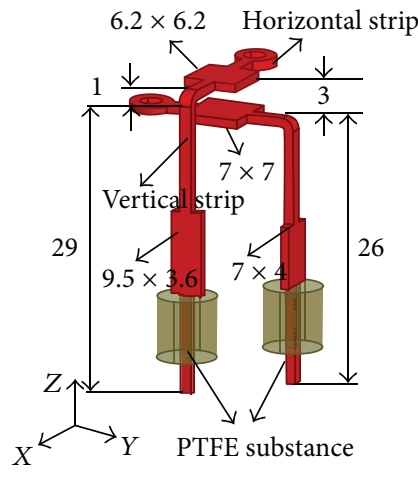

(d)

Figure 1: Geometry of the element: (a) 3D view, (b) side view, (c) detailed view of the crossed bowtie dipole, and (d) detailed view of the feed strips (unit: $\mathrm{mm}$ ).

fractional bandwidth of about $45.6 \%(1.76-2.80 \mathrm{GHz})$ is obtained for both polarizations for VSWR $\leq 1.5$ (Port 1 , $+45^{\circ}$ polarization, Port $2,-45^{\circ}$ polarization). To achieve a downtilted radiation pattern for base station applications, a 10-element linear antenna array based on the feed network and the element described above is designed. The measured results show that the array achieves a wide impedance fractional bandwidth of about 55.3\% (1.7$3.0 \mathrm{GHz}$ ) for $\mathrm{VSWR} \leq 1.5$ (Port $1,+45^{\circ}$ polarization), and VSWR $\leq 1.5$ (Port $2,-45^{\circ}$ polarization), which is wide enough for $3 \mathrm{G}$ and LTE applications. Moreover, the proposed array can realize a stable peak gain of about $16.5 \mathrm{~dB}$ over the entire operating bands. Particularly, by optimizing the distribution of amplitude and phase distribution along the feed, radiation pattern with a downtilted angle of about $6^{\circ}$ is obtained. Thus, the proposed array antenna is very suitable for potential base station applications.

\section{Crossed Bowtie Dipole Antenna Element}

2.1. Geometry of the Antenna Element. The geometry of the proposed dual-polarized crossed bowtie antenna element is illustrated in Figure 1. It consists of a pair of crossed bowtie dipoles, inverted L-shaped feed strips, a parasitic circular patch, four vertical metal cylinders, and a ground plane as a reflector to achieve the unidirectional radiation pattern. The crossed bowtie dipoles with colocated centers and orthogonal axe are used as radiators. Each bowtie dipole has a pair of square arms with a square hole located at the center of the arm. To improve impedance matching, the parasitic circular patch is employed on the top of the crossed bowtie dipole by adding another resonant mode in the upper band. The vertical metal cylinders have been introduced to reduce the dimensions along the array direction, which can weaken the array mutual coupling. The feed configuration, as shown in Figure 1(d), is an inverted L-shaped strip which is divided into two parts: a vertical strip and a horizontal strip. The vertical line with a hollow metal cylinder acts as a coaxial feeding line, whose outer conductor is connected to one arm of the dipole while an inner conductor is connected to the other arm. Furthermore, the inner core is shorted to the ground plane through the hollow metal cylinder, which is introduced to compensate the imbalance of the current amplitude. The feed mechanization of the other bowtie dipole is similar. Moreover, the two horizontal and orthogonal strips are staggered up and down. By adjusting the distance between the two orthogonal strips, the isolation of the two orthogonal polarizations is improved.

\subsection{Discussion of Parameters}

2.2.1. The Vertical Cylinder. To explore how the dimension of the vertical cylinder influences the antenna performance, parametric studies are performed as shown in Figure 2. The dependence of $\mathrm{H}_{2}$ on the VSWR of the dual-polarized antenna element is shown in Figure 2(a) and the simulated results for VSWR as a function of $D_{1}$ are shown in Figure 2(b). The VSWR of the antenna in the upper band is hardly affected by the length $\left(H_{2}\right)$ or the diameter $\left(D_{1}\right)$ of the vertical cylinder, while the lower band of the antenna 


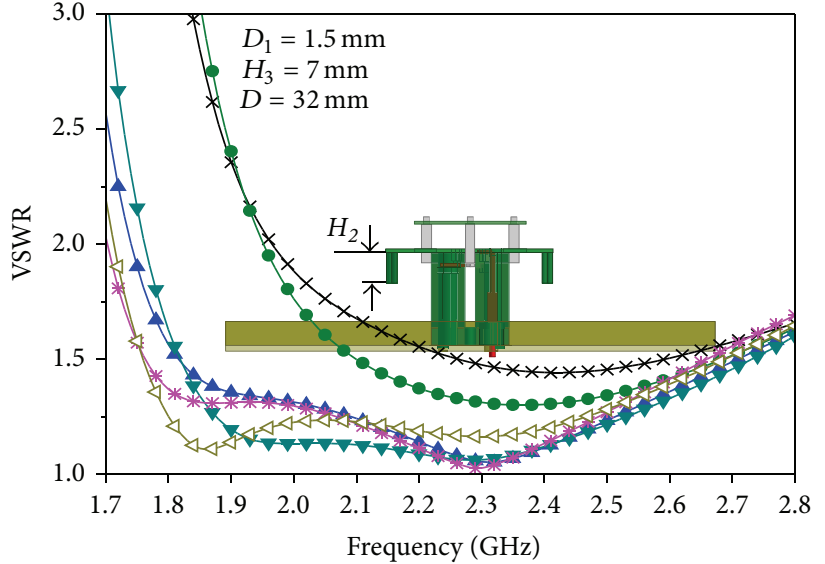

$$
\begin{array}{lll}
\rightarrow H_{2}=0 \mathrm{~mm} \text { Port } 1 & \rightarrow-H_{2}=10 \mathrm{~mm} \text { Port } 2 \\
\rightarrow-H_{2}=0 \mathrm{~mm} \text { Port } 2 & \rightarrow-H_{2}=12 \mathrm{~mm} \text { Port } 1 \\
\multimap-H_{2}=10 \mathrm{~mm} \text { Port } 1 & \neg-H_{2}=12 \mathrm{~mm} \text { Port } 2
\end{array}
$$

(a)

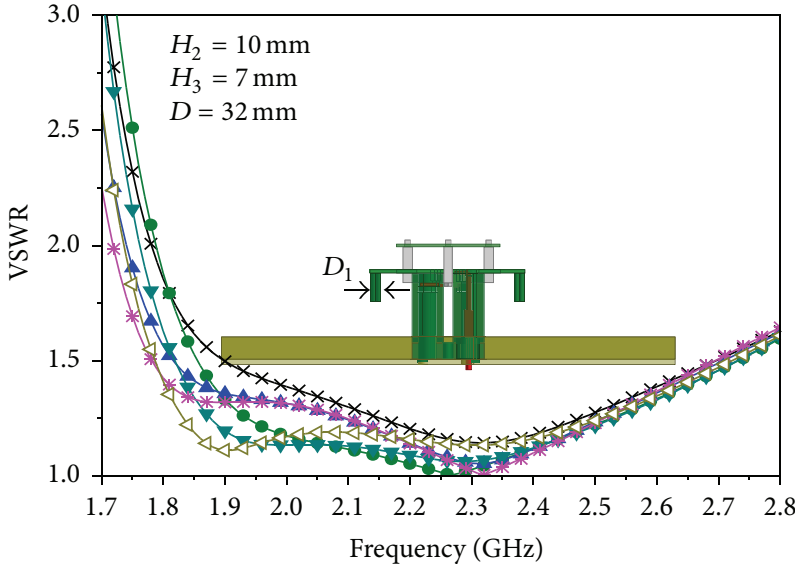

$$
\begin{array}{rlrl}
\star & D_{1}=1 \mathrm{~mm} \text { Port } 1 & \rightarrow & D_{1}=1.5 \mathrm{~mm} \text { Port } 2 \\
\multimap & D_{1}=1 \mathrm{~mm} \text { Port } 2 & \rightarrow & D_{1}=2 \mathrm{~mm} \text { Port } 1 \\
\multimap & D_{1}=1.5 \mathrm{~mm} \text { Port } 1 & \triangleleft D_{1}=2 \mathrm{~mm} \text { Port } 2
\end{array}
$$

(b)

Figure 2: Simulated VSWR for different values: (a) $H_{2}$ and (b) $D_{1}$.
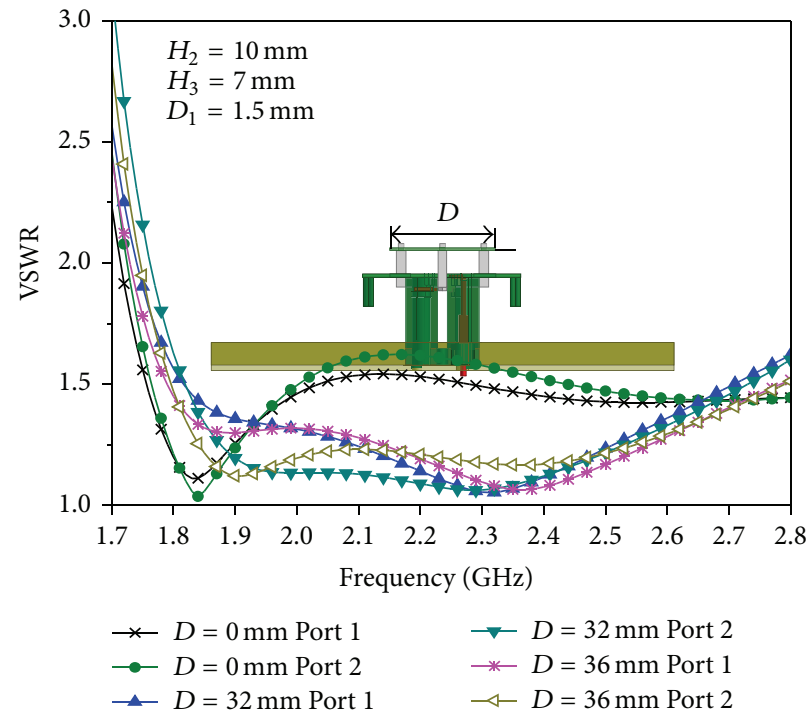

(a)

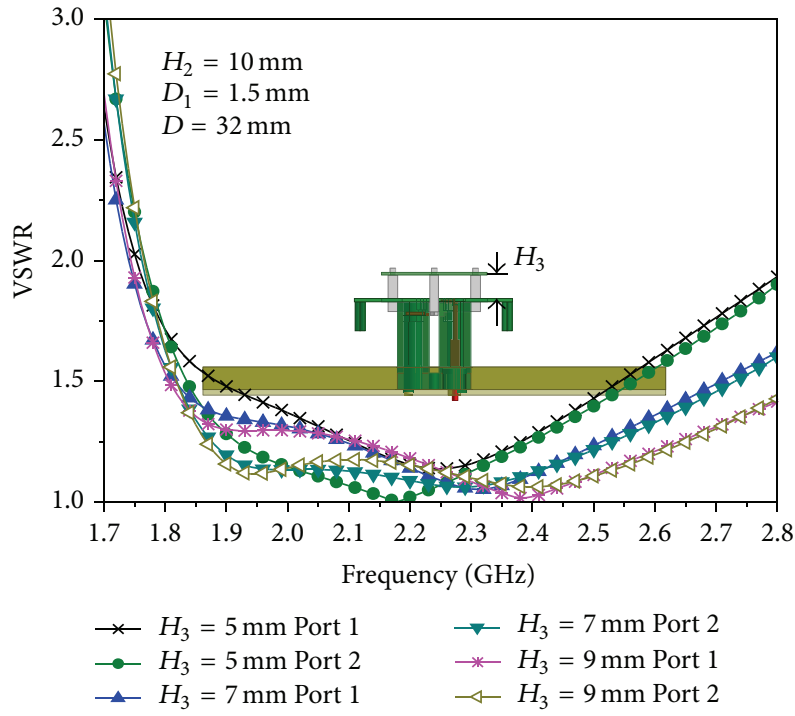

(b)

FIGURE 3: Simulated VSWR for different values: (a) $D$ and (b) $H_{3}$.

is affected significantly. When $H_{2}=0 \mathrm{~mm}$, which means that the vertical cylinders are removed, the resonant point of the antenna element is far from the lower band. By selecting $H_{2}=10 \mathrm{~mm}$ and $D_{1}=1.5 \mathrm{~mm}$, better impendence matching is achieved for the two ports which can meet the requirement for base station application.

2.2.2. The Parasitic Circular Patch. Considering the influence of the parasitic circular patch on the impedance bandwidth of the antenna, two key parameters are studied: the diameter of parasitic circular patch $(D)$ and the distance between patch and radiators $\left(\mathrm{H}_{3}\right)$, as depicted in Figure 3. Figure 3(a) shows the VSWR performance with different values of the diameter $D$. With a decrease in $D$, the resonant mode of the upper band is shifted to the lower band, whereas the resonant mode in the lower band changes slightly. With $D=0 \mathrm{~mm}$, which means that the parasitic circular patch is removed, only the antenna element achieves one resonant point in the operating band. In Figure 3(b), the antenna VSWR for different values of the distance $\mathrm{H}_{3}$ is presented. With an increase in $\mathrm{H}_{3}$, the coupling between patch and radiators tends to weaken. Hence, the resonant mode of the upper band is shifted to the upper band, whereas the resonant mode of the lower band is almost unchanged. Therefore, $D$ and $H_{3}$ mainly affect the resonant mode of the upper band. The optimal results of $D$ 


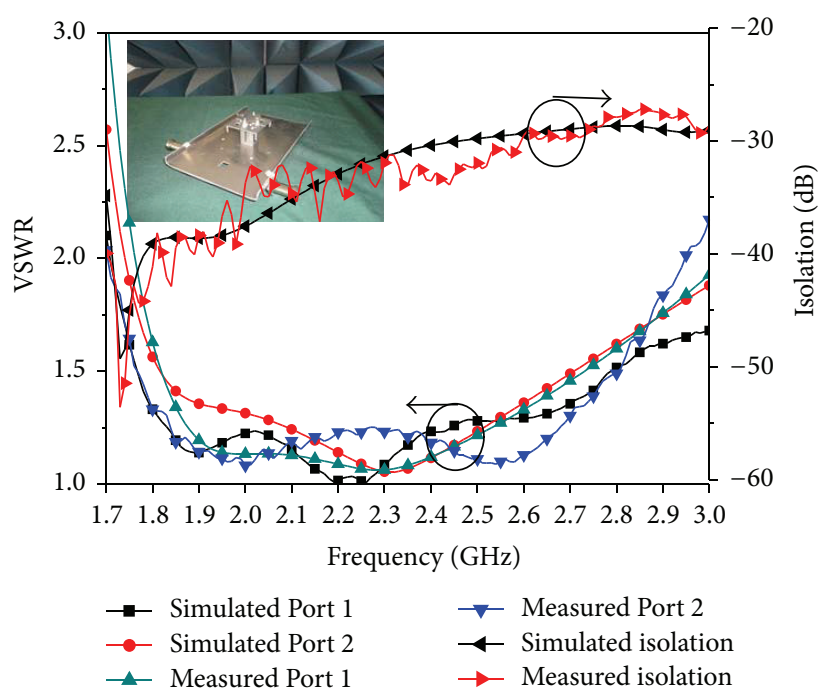

FIGURE 4: Simulated and measured VSWR and S21 against frequency.

TABLE 1: Amplitude and phase distribution along the feed.

\begin{tabular}{lccccccccccc}
\hline Number & 1 & 2 & 3 & 4 & 5 & 6 & 7 & 8 & 9 & 10 \\
\hline Amplitude & 0.612 & 0.801 & 0.978 & 1 & 0.960 & 0.723 & 0.871 & 0.825 & 0.609 & 0.631 \\
\hline Phase (deg) & 317 & 255 & 212 & 174 & 147 & 124 & 107 & 67 & 50 & 0 \\
\hline
\end{tabular}

and $H_{3}$ are $32 \mathrm{~mm}$ and $7 \mathrm{~mm}$ obtained by simulation for the proposed antenna. All other geometrical parameters of the dual-polarized crossed bowtie antenna element have been optimized with using the Ansoft HFSS 13.

2.3. Simulated and Measured Results. The dual-polarized crossed bowtie dipole antenna element is fabricated by die casting technique as shown in Figure 4. With using Aligent E8363B network analyzer the proposed antenna element is measured in the anechoic chamber. Figure 4 shows that the measured impedance fractional bandwidth for VSWR $\leq 1.5$ is $46.1 \%(1.76-2.81 \mathrm{GHz})$ for both polarizations. Obviously, wideband impedance characteristic is achieved. Both of the simulated and measured port isolations are better than $28 \mathrm{~dB}$ over the operating band. The discrepancy between the simulated and measured results is probably caused by fabrication tolerance.

The measured copolarization and cross-polarization patterns of the antenna element in the $\mathrm{XOZ}$ and $\mathrm{YOZ}$ planes at 1.8, 2.2, and 2.6 GHz are shown in Figure 5. In the operating band, the half-power beam widths of the copolarization pattern in the XOZ plane (the horizontal plane) are about $66^{\circ}$. Moreover, the measured results have maximum crosspolarization level of about $-18 \mathrm{~dB}$ in the XOZ plane; the frontto-back ratio is better than $22 \mathrm{~dB}$ over the entire band. Note that both of the two ports can achieve a gain over $8.3 \mathrm{~dB}$ with a variation of $1 \mathrm{~dB}$ over the entire band.

\section{Dual-Polarized Array}

3.1. Array Antenna Configuration. The configuration of the proposed array antenna is shown in Figure 6. The array antenna is composed of a wideband feed network, a ground plane, and ten dual-polarized antenna elements as described in Section 2. The array antenna is mounted on the center of the ground plane with dimensions of $1135 \times 55 \mathrm{~mm}^{2}$ and the space between neighboring elements is $115 \mathrm{~mm}$ as shown in Figures 6(a) and 6(b). A pair of side walls is also introduced to reduce the backside radiation and septum is used to improve the isolation performance between the neighboring elements. For the feed network in Figure 6(c), it is fabricated on a PTFE substrate with a thickness of $0.93 \mathrm{~mm}$, a relative dielectric constant of 2.6, and a loss tangent of 0.001 . To achieve a downtilted pattern for base station applications, amplitude and phase distribution along the feed are optimized with using the adaptive differential evolution algorithm, which incorporated a new select operator and an adaptive parameter and is introduced to search the global solutions. Finally, the optimal results about the amplitude and phase of the feed network are tabulated in Table 1 .

3.2. Results of Simulation and Measurement. The simulated and measured VSWR against frequency are shown in Figure 7. For VSWR $\leq 1.5$, the measured impedance fractional bandwidth is about $55.3 \%$ ranging from 1.7 to $3 \mathrm{GHz}$ for both polarizations. Additionally, both simulated 

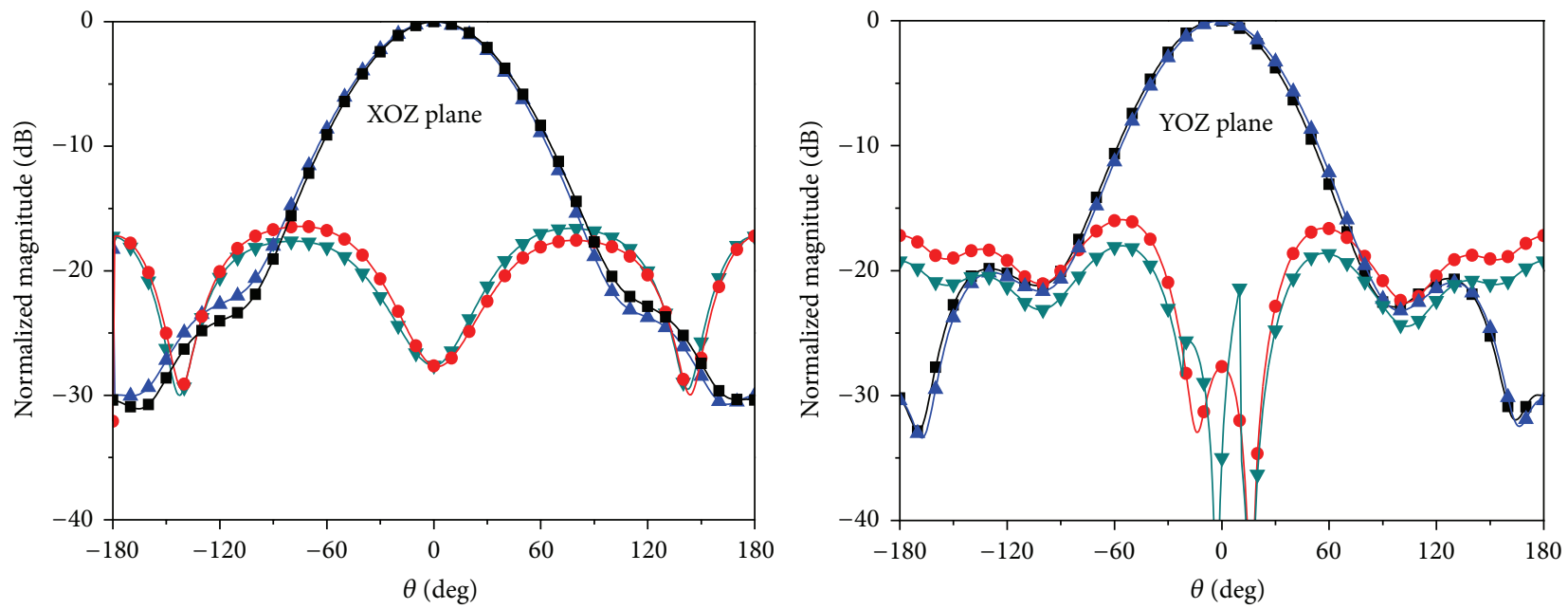

(a)
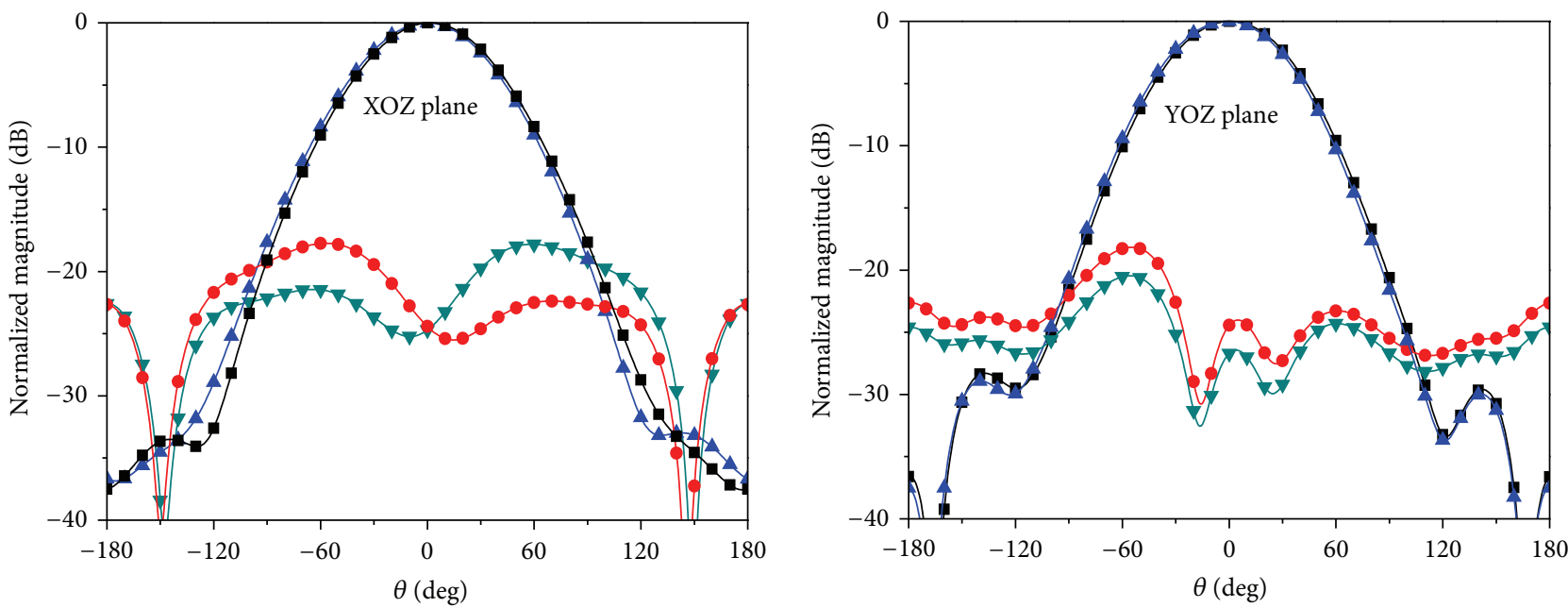

(b)
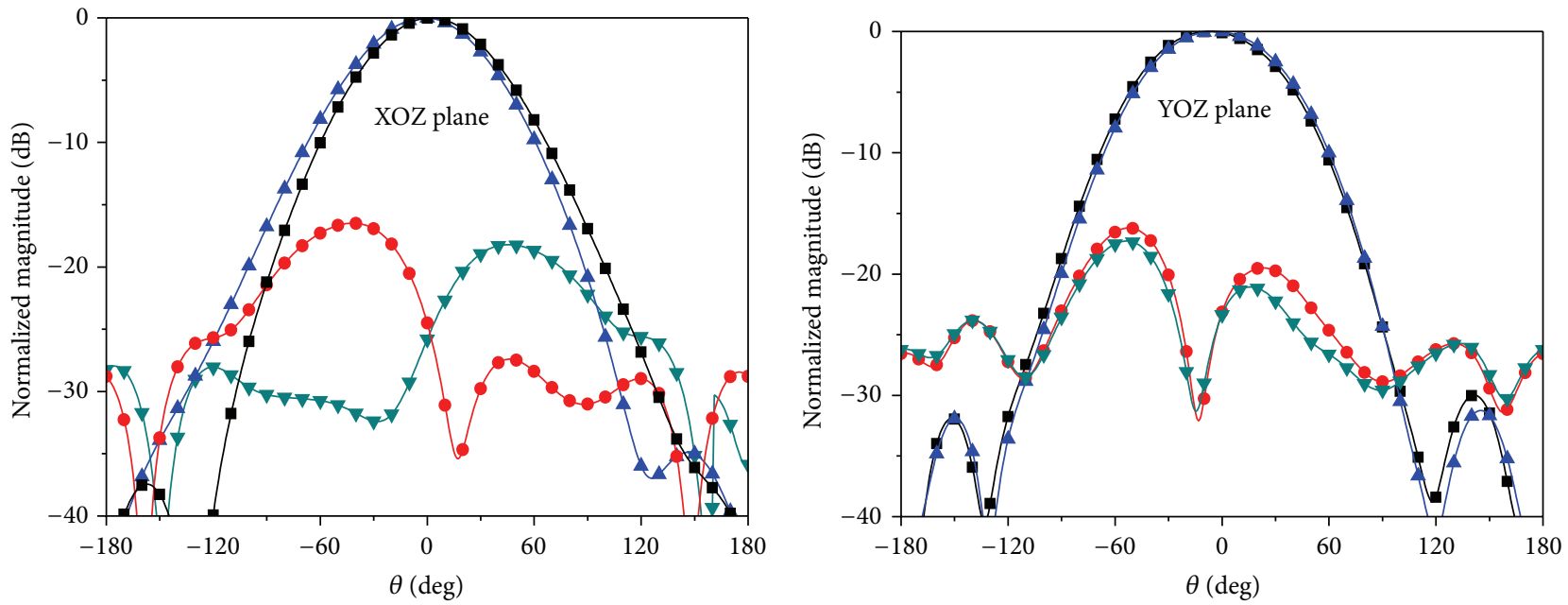

- Copol. Port $1 \longrightarrow$ Copol. Port 2

$\rightarrow$ Cross-pol. Port $1 \rightarrow$ Cross-pol. Port 2

— Copol. Port $1 \longrightarrow$ Copol. Port 2

$\rightarrow$ Cross-pol. Port $1 \rightarrow$ Cross-pol. Port 2

(c)

FIGURE 5: Measured radiation patterns for the element at (a) 1.8, (b) 2.2, and (c) $2.6 \mathrm{GHz}$. 


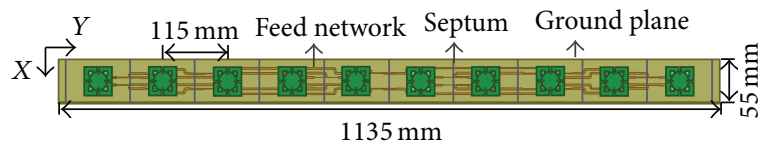

(a)

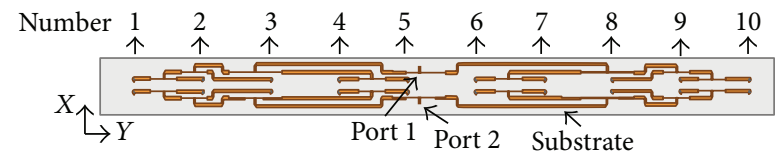

(c)

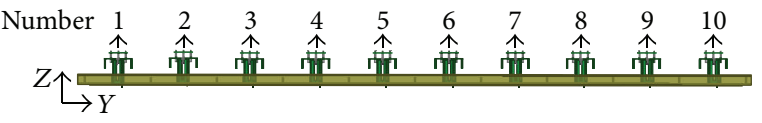

(b)

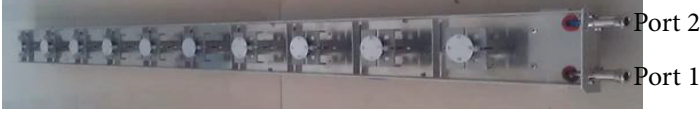

(d)

Figure 6: Configuration of the proposed array: (a) top view, (b) side view, (c) feed network, and (d) prototype of the array.

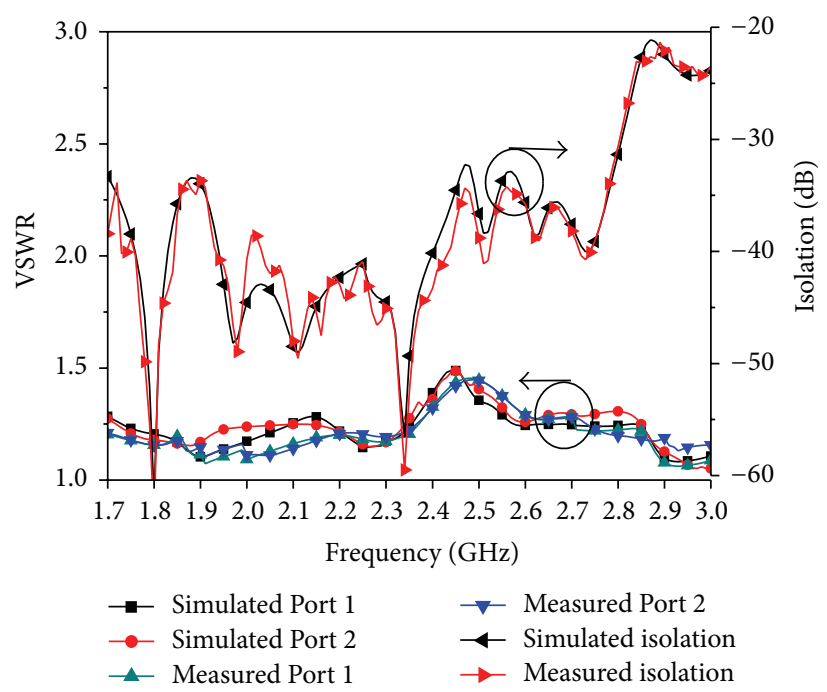

FIGURE 7: Simulated and measured results for the isolation and VSWR.

and measured port isolations are better than $30 \mathrm{~dB}$ over the $3 \mathrm{G}$ and LTE bands. The difference between simulated and measured values is due to fabrication tolerances and measurement environment.

Figure 8 shows the measured radiation patterns of the proposed array at $1.8,2.2$, and $2.6 \mathrm{GHz}$. A downtilted radiation pattern of $6^{\circ}$ for the two ports is obtained in the $\mathrm{XOZ}$ plane by application of adaptive differential evolution algorithm. Moreover, the cross-polarization component of radiation pattern is better than $-20 \mathrm{~dB}$ and front-to-back ratio is better than $30 \mathrm{~dB}$ over the operating band. Thanks to the existence of the side walls, the side lobe level of the array is less than $-10 \mathrm{~dB}$. Additionally, the half-power beam width of the copolar patterns in the YOZ plane is about $66^{\circ}$ over the whole band. Measured gains for the two ports are shown in Figure 9. It was observed that measured gain is better than $16 \mathrm{~dB}$ over the entire band. The measurements prove that the array antenna can be widely used in the mobile communication service.

\section{Conclusion}

A wideband dual-polarized crossed bowtie dipole array with downtilted pattern is proposed. The array consists ofa wideband feed network, a ground plane, and ten dual-polarized antenna elements. To achieve a downtilted radiation pattern for base station applications, amplitude and phase distribution along the feed are optimized by application of adaptive differential evolution algorithm. The measured results show that the dual-polarized array achieves a wide impedance bandwidth and good radiation characteristics covering the frequency bands for $3 \mathrm{G}$ and LTE systems. Therefore, the proposed array antenna is very suitable for potential wireless communication applications.

\section{Conflict of Interests}

The authors declare that there is no conflict of interests regarding to the publication of this paper. 

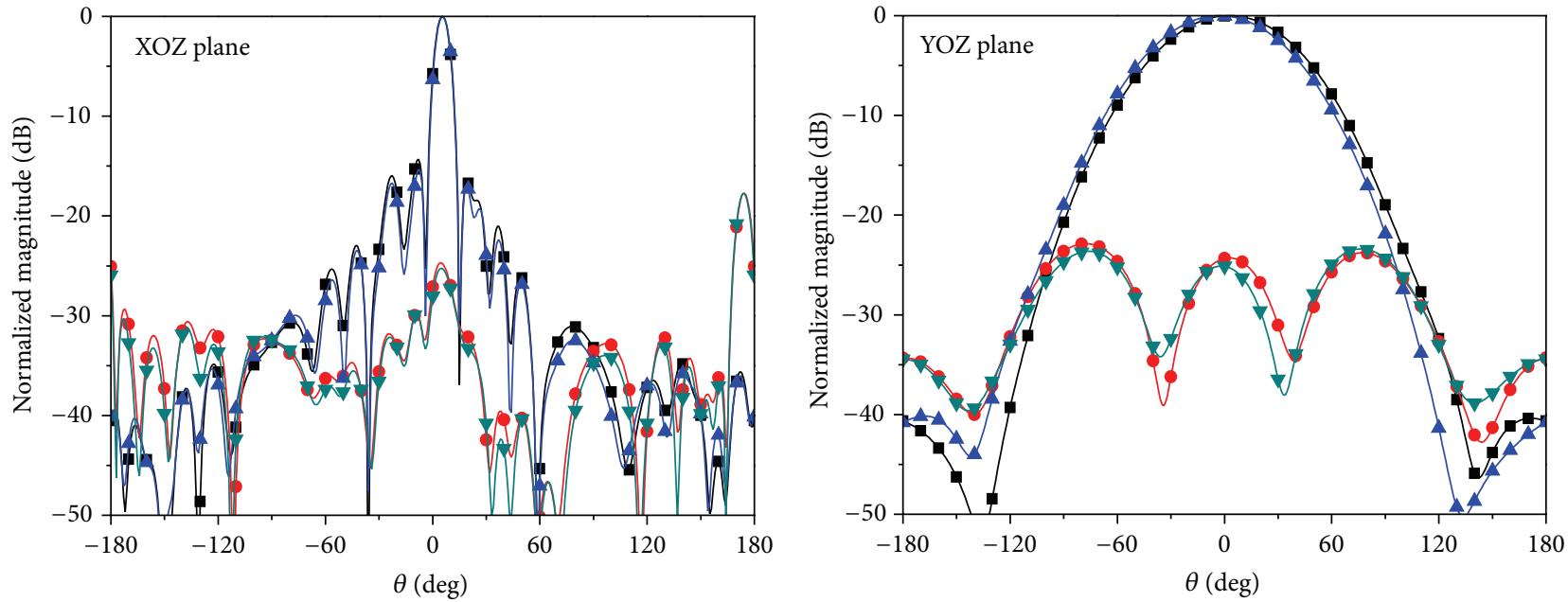

(a)
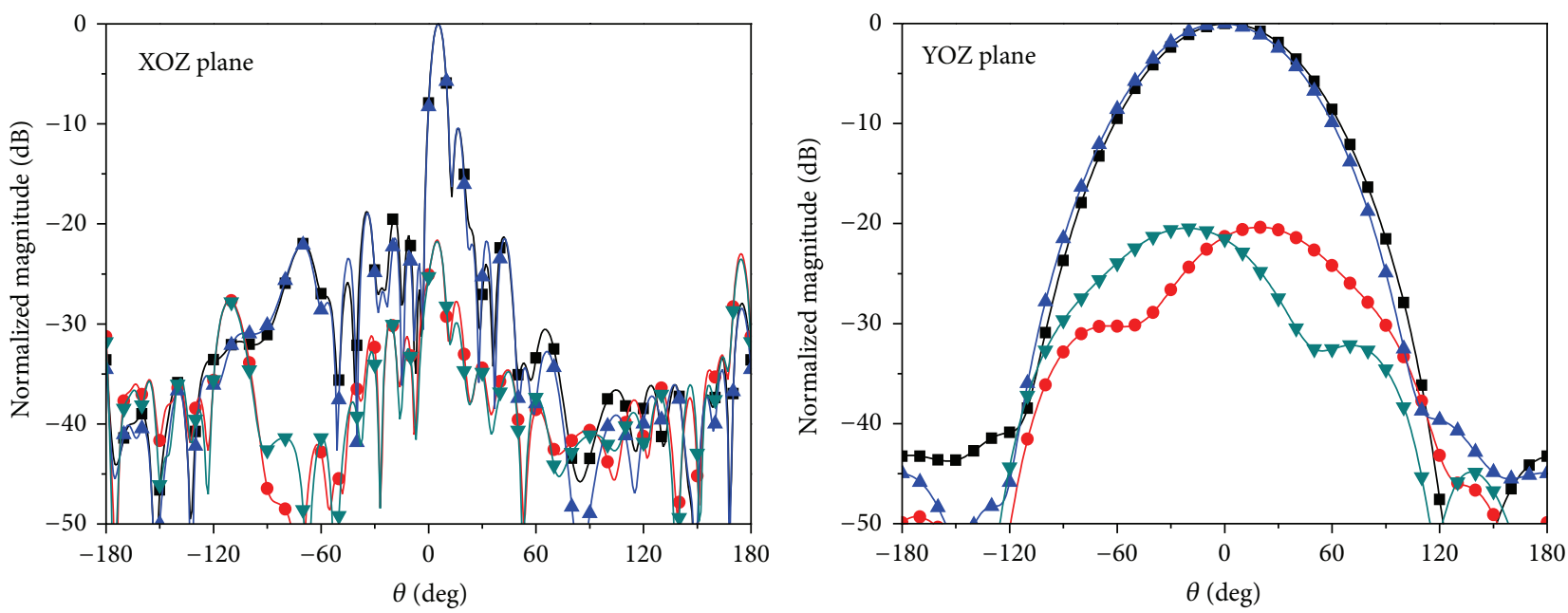

(b)
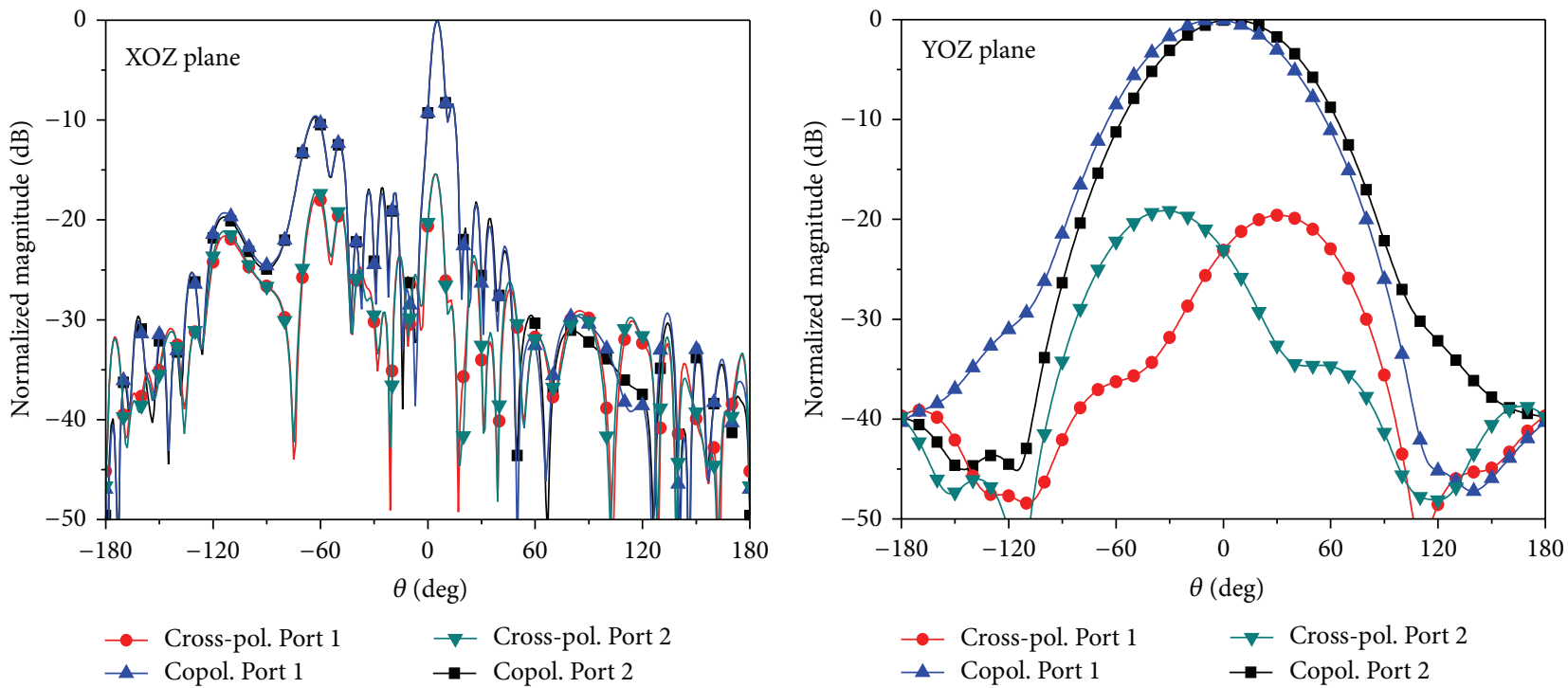

(c)

FIGURE 8: Measured radiation patterns for the dual-polarized antenna array at (a) 1.8, (b) 2.2, and (c) $2.6 \mathrm{GHz}$. 


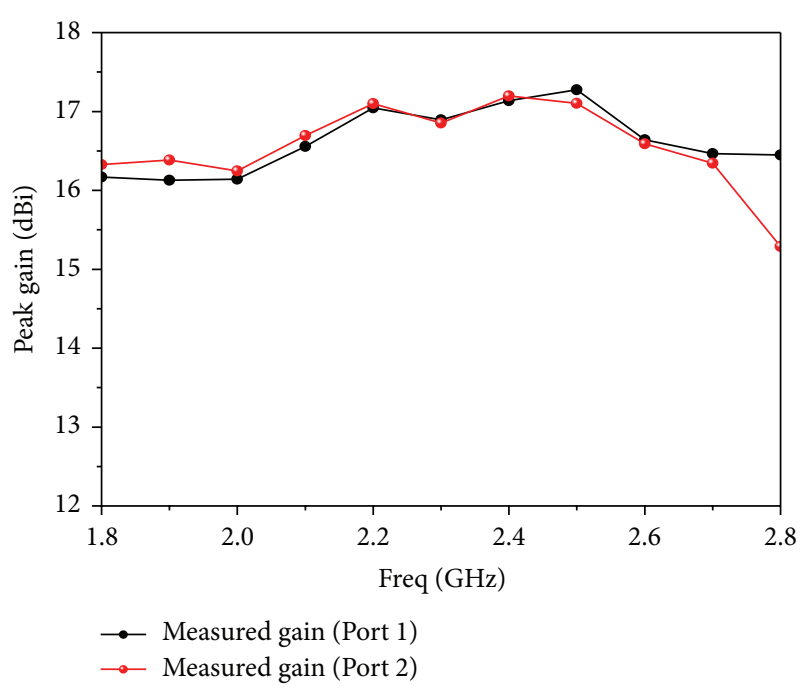

Figure 9: Measured gain of Port 1 and Port 2.

\section{Acknowledgments}

The authors would like to thank TTCOM for kindly support. This work was supported by the Fundamental Research Funds for the Central Universities (nos. K5051302033, K5051307009, and K5051310004), National Natural Science Foundation of China (Grant no. 61301175), and Natural Science Basic Research Plan in Shaanxi Province of China (Program no. 2014JQ8311).

\section{References}

[1] S. Chen, Y. Wang, W. Ma, and J. Chen, "Technical innovations promoting standard evolution: from TD-SCDMA to TD-LTE and beyond," IEEE Wireless Communications, vol. 19, no. 1, pp. 60-66, 2012.

[2] B. Huang, "Coexistence studies for LTE-FDD with TD-LTE in the band 2500-1690 MHz," in Proceedings of the IET International Conference on Communication Technology and Application (ICCTA '11), pp. 411-416, Beijing, China, 2011.

[3] S.-W. Kim and K.-Y. Kim, "Physical layer verification for 3GPP LTE (FDD)," in Proceedings of the 11th International Conference on Advanced Communication Technology (ICACT '09), pp. 1095-1100, February 2009.

[4] Y. Liang, J. Zhang, Y. Zhang, and X. Nie, "Investigation of polarization configurations and the impacts on fading correlation characteristics," in Proceedings of the IEEE 70th Vehicular Technology Conference Fall (VTC '09), Anchorage, Alaska, USA, September 2009.

[5] Y. Li, M. Peng, and J. Jiang, "Investigation of dual-polarization antenna scheme in TD-LTE systems," in Proceedings of the IEEE International Conference on Wireless Information Technology and Systems (ICWITS '12), pp. 1-4, Maui, Hawaii, USA, November 2012.

[6] X. Quan and R. Li, "A broadband dual-polarized omnidirectional antenna for base stations," IEEE Transactions on Antennas and Propagation, vol. 61, no. 2, pp. 943-947, 2013.

[7] B. Wu and K.-M. Luk, "A 4-port diversity antenna with high isolation for mobile communications," IEEE Transactions on Antennas and Propagation, vol. 59, no. 5, pp. 1660-1667, 2011.
[8] S.-G. Zhou, P.-K. Tan, and T.-H. Chio, "Low-profile, wideband dual-polarized antenna with high isolation and low cross polarization," IEEE Antennas and Wireless Propagation Letters, vol. 11, pp. 1032-1035, 2012.

[9] J.-J. Xie, Y.-Z. Yin, J.-H. Wang, and X.-L. Liu, "Wideband dualpolarised electromagneticfed patch antenna with high isolation and low cross-polarisation," Electronics Letters, vol. 49, no. 3, pp. 171-173, 2013.

[10] M. Taguchi and S. Sato, "Wideband base station antenna composed of ultra low profile inverted L antenna for mobile phone," in Proceedings of the 2nd IEEE-APS Topical Conference on Antennas and Propagation in Wireless Communications (APWC '12), pp. 902-905, September 2012.

[11] J.-Y. Deng, Y.-Z. Yin, K. Song, H. Gao, and Q.-Z. Liu, "Broadband double-tuned element with low profile for base station antennas," Electronics Letters, vol. 46, no. 3, pp. 192-194, 2010.

[12] W. X. An, H. Wong, K. L. Lau, S. F. Li, and Q. Xue, "Design of broadband dual-band dipole for base station antenna," IEEE Transactions on Antennas and Propagation, vol. 60, no. 3, pp. 1592-1595, 2012.

[13] W. Luo, S. Yang, and Z. Nie, "A wideband and dual polarization base station antenna for IMT-advanced system," in Proceedings of the Cross Strait Quad-Regional Radio Science and Wireless Technology Conference (CSQRWC '11), pp. 483-486, Harbin, China, July 2011.

[14] B. Li, Y. Z. Yin, W. Hu, Y. Ding, and Y. Zhao, "Wideband dualpolarized patch antenna with low cross polarization and high isolation," IEEE Antennas and Wireless Propagation Letters, vol. 11, pp. 427-430, 2012.

[15] Q. Xin, F. Zhang, B. Sun, Y. Zou, and Q. Liu, "A novel dual-band Yagi-Uda antenna for wireless communications," in Proceedings of the 9th International Symposium on Antennas Propagation and EM Theory (ISAPE '10), pp. 289-292, November-December 2010.

[16] S. Nikmehr and K. Moradi, "Design and simulation of triple band GSM900/DCS1800/UMTS2100 MHz microstrip antenna for base station," in Proceedings of the 12th IEEE International Conference on Communication Systems (ICCS '10), pp. 113-116, November 2010.

[17] B. Q. Wu and K. M. Luk, "A wideband, low-profile, conicalbeam antenna with horizontal polarization for indoor wireless communications," IEEE Antennas and Wireless Propagation Letters, vol. 8, pp. 634-636, 2009.

[18] B. Q. Wu and K.-M. Luk, "A broadband dual-polarized magneto-electric dipole antenna with simple feeds," IEEE Antennas and Wireless Propagation Letters, vol. 8, pp. 60-63, 2009.

[19] X. X. Guo and Q. X. Chu, "Wideband dual-polarized base station antenna with high isolation and low cross polarization for LTE communication system," in Proceedings of the IEEE International Wireless Symposium (IWS '13), pp. 1-3, April 2013.

[20] D. Sugimura, M. Arai, K. Sakaguchi, K. Araki, and T. Sotoyama, "A study on beam tilt angle of base station antennas for base station cooperation systems," in Proceedings of the IEEE 22nd International Symposium on Personal, Indoor and Mobile Radio Communications (PIMRC '11), pp. 2374-2378, Toronto, Canada, September 2011.

[21] I. Kim and Y. Rahmat-Samii, "EBG-dipole array antenna creating beam-tilt for base-station applications," in Proceedings of the US National Committee of URSI National Radio Science Meeting (USNC-URSI NRSM '13), pp. 1-4, Boulder, Colo, USA, January 2013. 

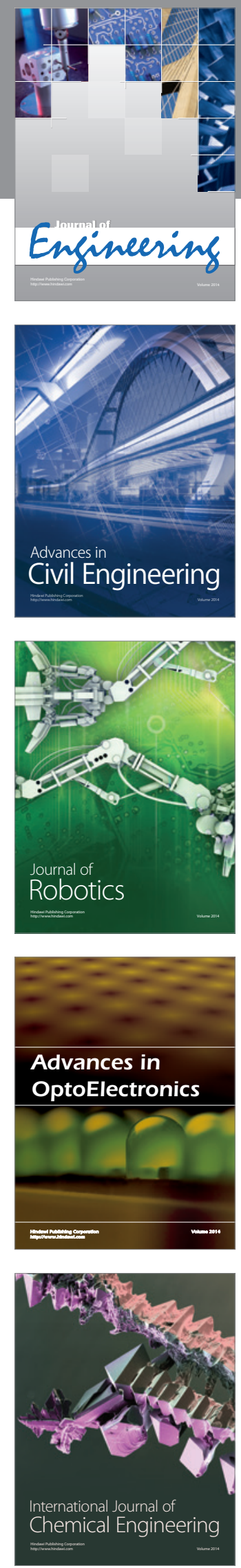

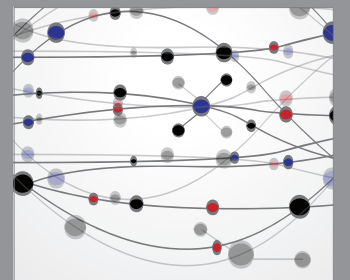

The Scientific World Journal
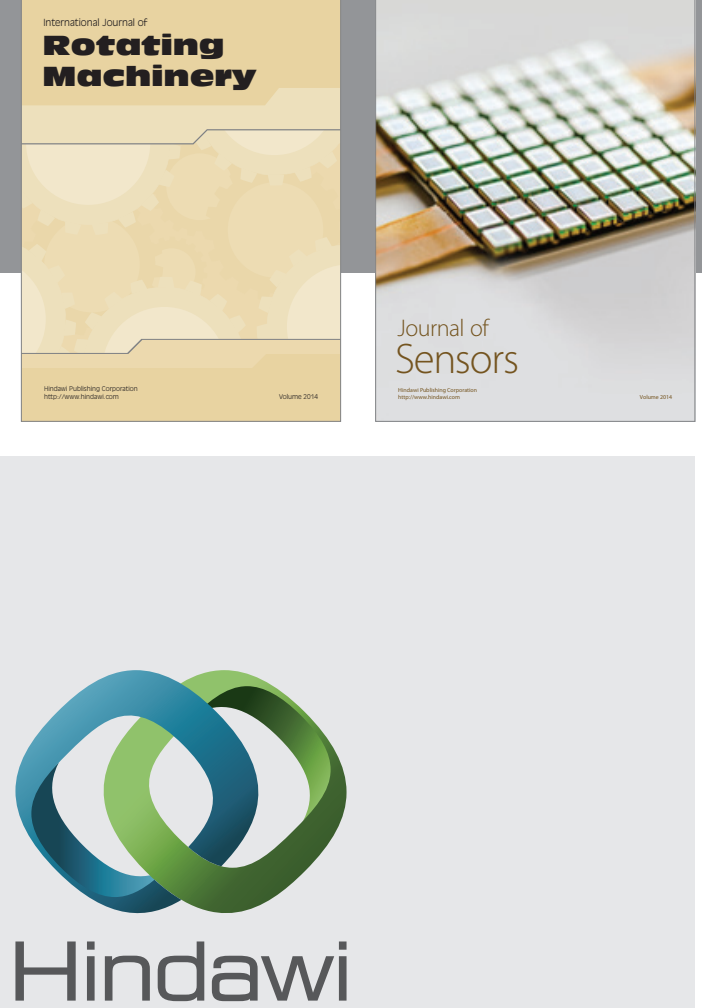

Submit your manuscripts at http://www.hindawi.com
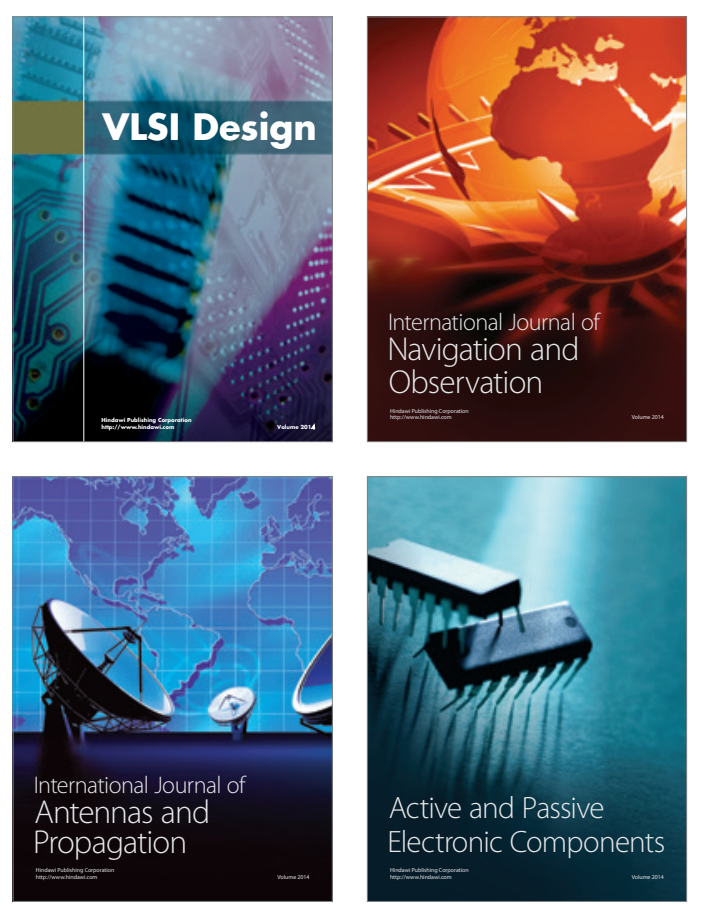
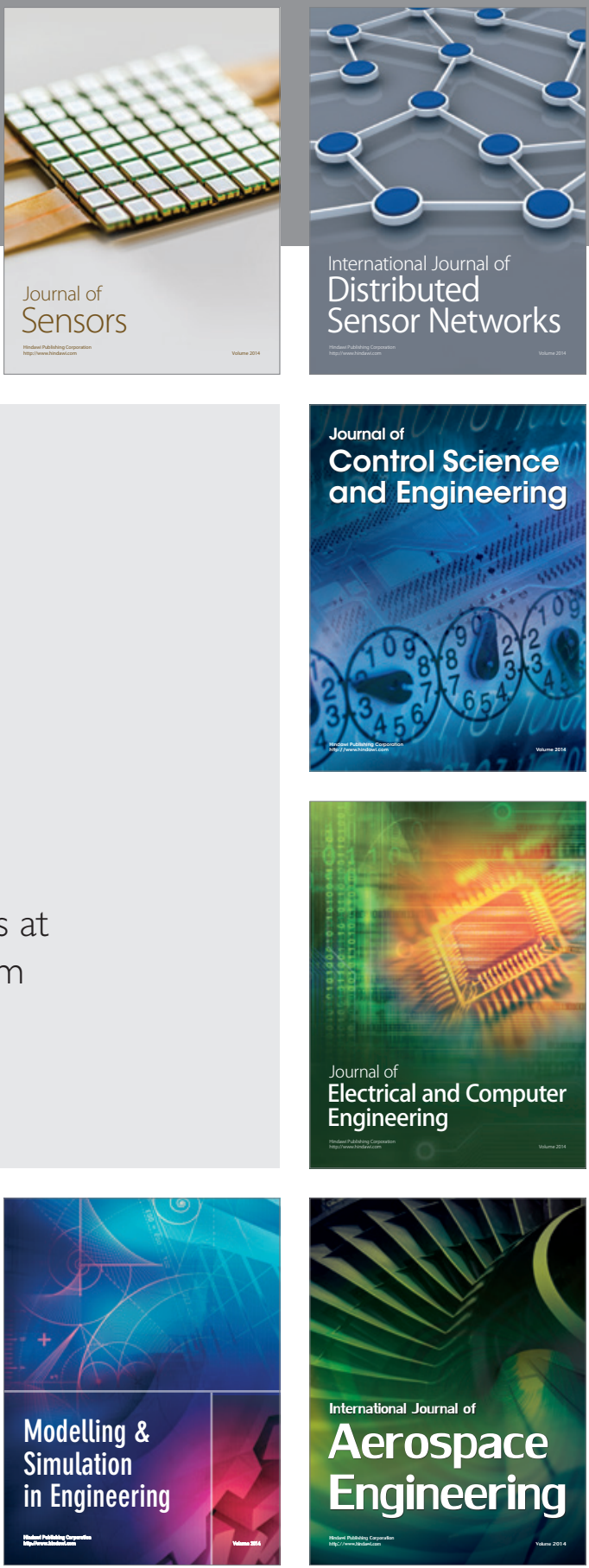

Journal of

Control Science

and Engineering
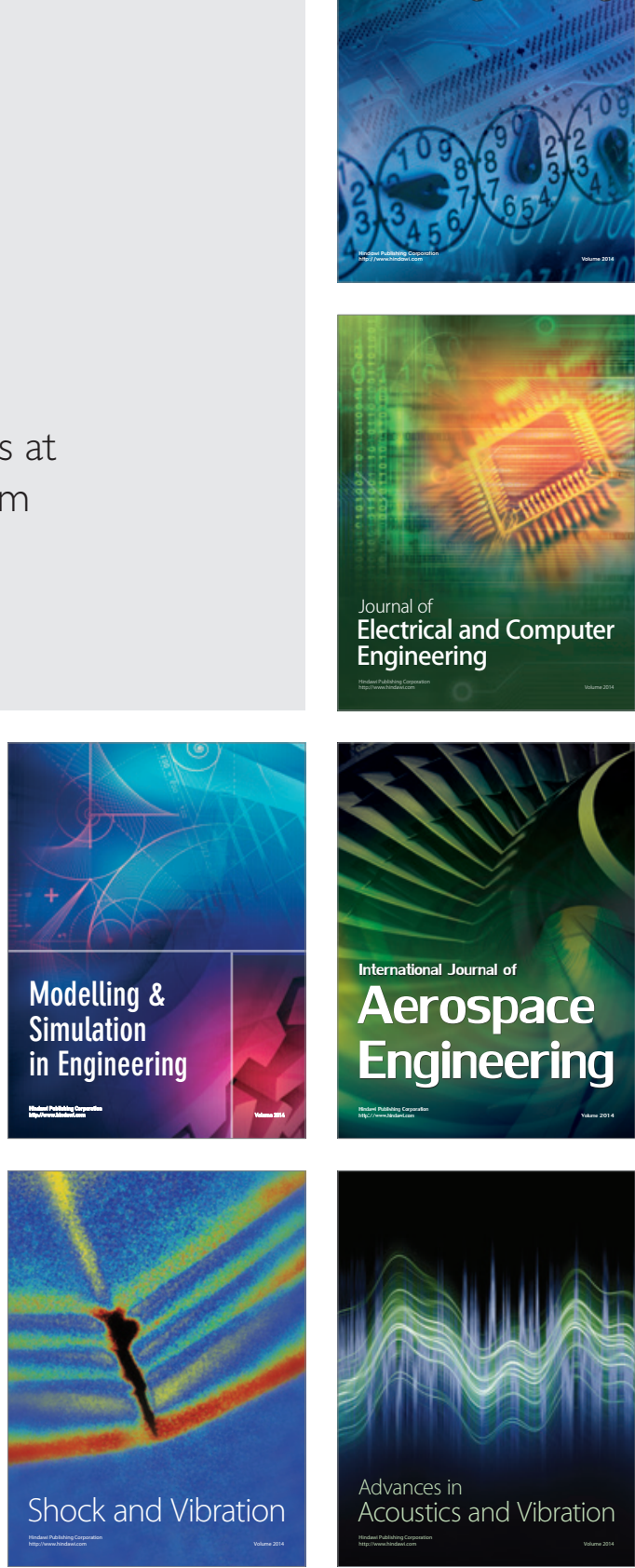